\title{
Dismantlable adhesion properties of reactive acrylic copolymers resulting from cross-linking and gas evolution
}

Eriko Sato, Shusei Iki, Keisuke Yamanishi, Hideo Horibe,

Akikazu Matsumoto

\begin{tabular}{|c|l|}
\hline Citation & The Journal of Adhesion. 93(10): 811-822 \\
\hline Issue Date & $2016-08-18$ \\
\hline Type & Journal Article \\
\hline Textversion & author \\
\hline Relation & $\begin{array}{l}\text { This is an Accepted Manuscript of an article published by Taylor \& Francis in The } \\
\text { Journal of Adhesion on 18/08/2016, available online: } \\
\text { https://doi.org/10.1080/00218464.2016.1209114 . }\end{array}$ \\
\hline DOI & $10.1080 / 00218464.2016 .1209114$ \\
\hline
\end{tabular}

\author{
Self-Archiving by Author(s) \\ Placed on: Osaka City University
}

SATO, E., IKI, S., YAMANISHI, K., HORIBE, H., \& MATSUMOTO, A. (2017). Dismantlable adhesion properties of reactive acrylic copolymers resulting from cross-linking and gas evolution. The Journal of Adhesion. 93, 811-822. 


\section{Dismantlable Adhesion Properties of Reactive Acrylic Copolymers Resulting from Cross-linking and Gas Evolution}

Eriko Sato, ${ }^{1 *}$ Shusei Iki, ${ }^{1}$ Keisuke Yamanishi, ${ }^{1}$ Hideo Horibe, ${ }^{1}$ and Akikazu Matsumoto $^{2 *}$

${ }^{1}$ Department of Applied Chemistry and Bioengineering, Graduate School of Engineering, Osaka City University,

3-3-138 Sugimoto, Sumiyoshi-ku, Osaka 558-8585, Japan

${ }^{2}$ Department of Applied Chemistry, Graduate School of Engineering, Osaka Prefecture University,

1-1 Gakuen-cho, Naka-ku, Sakai-shi, Osaka 599-8531, Japan

Corresponding authors

Eriko Sato

Department of Applied Chemistry and Bioengineering, Graduate School of Engineering, Osaka City University,3-3-138 Sugimoto, Sumiyoshi-ku, Osaka 558-8585, Japan sato@a-chem.eng.osaka-cu.ac.jp

Tel \& Fax: +81-6-6605-2982

Akikazu Matsumoto

Department of Applied Chemistry, Graduate School of Engineering, Osaka Prefecture University, Gakuen-cho, Naka-ku, Sakai-shi, Osaka 599-8531, Japan

matsumoto@chem.osakafu-u.ac.jp

Tel \& Fax: +81-72-254-9292 


\section{Dismantlable Adhesion Properties of Reactive Acrylic Copolymers Resulting from Cross-linking and Gas Evolution}

The acrylic copolymers involving 2-hydroxyethyl acrylate (HEA) and tertbutyl acrylate (tBA) units as reactive units behave as pressure-sensitive adhesive type dismantlable adhesive materials. In order to clarify the individual role of HEA and tBA units on dismantlability, the $180^{\circ}$ peel behavior after the dismantling treatment, i.e., heating in the presence of given amount of acid catalysts, was systematically investigated using the acrylic copolymers involving different amounts of the reactive units. It was revealed that transesterification of HEA units resulted in an increase in the cohesive force and modulus due to an increase in the molecular weight and cross-linking. Deprotection of tBA units, i.e, transformation of tBA to acrylic acid unit with isobutene evolution, promoted cross-linking by the esterification of acrylic acid units and tended to reduce a cohesive force by forming voids in the adhesive layer due to the evolution of isobutene gas. Interfacial failure in the peel tests corresponded with a high degree of cross-linking and increased modulus of the adhesive. Conversely, cohesive failure was associated with reduced cohesive strength of the adhesive layer and a low peel strength.

Keywords: Pressure-sensitive; Peel; Recycling; Deprotection; Transesterification

\section{Introduction}

Dismantlable adhesives have attracted attention in the fields of material recycling and temporary bonding. Dismantlable adhesives require both a strong bonding strength without deterioration during use and a quick reduction in the bonding strength ondemand. In order to satisfy the conflicting requirement, various dismantling methods and adhesive materials are reported, i.e., UV and visible light curable polymers,[1, 2] chemically and photo degradable polymers,[3-6] thermally expansive microcapsules,[7] 
isomerizable azobenzene derivatives,[8] electrochemically reactive moieties,[9,10] shape memory polymers,[11,12] and polyelectrolyte brushes[13].

Recently we reported pressure-sensitive adhesive (PSA) type dismantlable adhesive systems responding to dual stimuli, UV irradiation and subsequent heating, using reactive acrylic copolymers containing tert-butyl acrylate (tBA) and 2-hydroxyethyl acrylate (HEA) units[14-18]. It was revealed that tBA and HEA units in the copolymers undergo deprotection and transesterification, respectively, and the reactions are catalyzed by acids[14,16]. Therefore, a photo-acid generator (PAG) was utilized instead of an acid in order to achieve high thermal stabilities before acid generation and high reactivities after acid generation by photoirradiation. The peel strength of the reactive acrylic copolymers containing a PAG did not decrease after one of the treatments, i.e., photoirradiation or heating, whereas significant reduction in the peel strength was achieved by the dual stimuli, i.e., photoirradiation with subsequent heating[14,15,18]. Furthermore, it was found that the block copolymers involving a poly(tert-butyl acrylate) segment are superior in terms of the time required to dismantle and failure modes[14,17,18]. In the reactive acrylic copolymers, deprotection of tBA units results in the formation of acrylic acid (AA) units and isobutene gas evolution, and transesterification results in cross-linking. The property changes caused by these reactions are considered to be a driving force to reduce the bonding strength. However, the individual role of tBA and HEA units on the dismantlable behavior is not completely understood. In this study, in order to clarify the role of tBA and HEA units, dismantlable adhesion properties resulting from each reaction of tBA and HEA units, i.e., deprotection and transesterification, were investigated in detail. First, the effects of the extent of transesterification on peel strengths were studied by using the acrylic copolymers containing the different amounts of HEA unit in the presence of the 
different amounts of acid catalysts. Then, the effects of the deprotection of tBA units were investigated in terms of the promotion of the cross-linking.

\section{Experimental}

\subsection{Materials}

tBA, HEA, 2-ethylhexyl acrylate (2EHA), and n-butyl acrylate (nBA) were purchased from Tokyo Chemical Industry Co., Ltd. (Tokyo, Japan), and distilled under reduced pressure prior to use. 2,2'-Azobis(4-methoxy-2,4-dimethylvaleronitrile) (AMVN) and 2,2'-azobis(isobutyronitrile) (AIBN) were purchased from Wako Pure Chemicals Co., Ltd. (Osaka, Japan), and recrystallized from methanol. Diphenyl ditelluride (DT-Ph, 96.0\%, Tokyo Chemical Industry Co. Ltd. (Tokyo, Japan)) and $N$ hydroxynaphthalimide triflate (NIT, 99\%, Sigma-Aldrich Japan llc. (Tokyo, Japan)) was used as received. Di- $n$-butyl ditelluride (DT-Bu) were synthesized according to methods described in the literature[19]. All copolymers were synthesized by the organotellurium-mediated living radical polymerization (TERP). Other reagents and solvents were used without further purification.

\subsection{Synthesis of Reactive Acrylic Copolymers by Living Radical Polymerization}

Polymerizations were carried out according to our previous report on TERP using ditellurides and binary azo initiators.[14] A typical polymerization procedure was as follows. To a 10-mL glass tube, tBA (3.00 g), nBA (6.48 g), HEA (0.46 g), AMVN (5.2 mg), AIBN (2.3 mg), and DT-Bu (2.9 $\mu \mathrm{L})$ in $9.91 \mathrm{~g}$ of anisole were added, and the solution was stirred with argon bubbling at $0{ }^{\circ} \mathrm{C}$ for $30 \mathrm{~min}$. The polymerization was carried out at $60{ }^{\circ} \mathrm{C}$ for $5.5 \mathrm{~h}$. The conversions of tBA, nBA, and HEA were 81,75 , and $62 \%$, respectively. The number-average molecular weight $\left(M_{\mathrm{n}}\right)$, and the molecular 
weight distribution $\left(M_{\mathrm{w}} / M_{\mathrm{n}}\right)$ values were $2.57 \times 10^{5}$ and 1.48 , respectively. The copolymer was isolated using a methanol-water mixture (90/10 in volume ratio) as the precipitant and the composition was determined by ${ }^{1} \mathrm{H}$ NMR spectra. The conditions and the results of the polymerization for the polymer used in this study are summarized in Table 1.

\subsection{Deprotection of P(tBA-co-nBA-co-HEA)}

To a $50-\mathrm{mL}$ round bottom flask, $\mathrm{P}\left(\mathrm{tBA}_{30.5}-c o-\mathrm{nBA}_{64.0}-c o-\mathrm{HEA}_{5.5}\right)(1.14 \mathrm{~g})$ and trifluoroacetic acid (1.62 g) in $15 \mathrm{~mL}$ of dichloromethane were added, and the solution was stirred at room temperature for 24 h to carry out deprotection of tBA unit, i.e., transformation to AA units with evolution of isobutene. The hydrolyzed polymer $\left(\mathrm{P}\left(\mathrm{AA}_{30.5}-c o-\mathrm{nBA}_{64.0}-c o-\mathrm{HEA}_{5.5}\right)\right.$ ) was purified by 3 times reprecipitation in a 50 -fold volume of $n$-hexane using chloroform as a good solvent. The $M_{\mathrm{n}}$, and $M_{\mathrm{w}} / M_{\mathrm{n}}$ values were $2.81 \times 10^{5}$ and 1.85 , respectively.

\subsection{Measurements}

The number- and weight-average molecular weights $\left(M_{\mathrm{n}}\right.$ and $\left.M_{\mathrm{w}}\right)$ were determined by gel permeation chromatography (GPC) in tetrahydrofuran (THF) as the eluent using a Tosoh CCPD RE-8020 system and calibration with standard polystyrenes. The ${ }^{1} \mathrm{H}$ NMR spectra were recorded by a Bruker AV300N spectrometer. The thermogravimetric and differential thermal analyses (TG/DTA) were performed using a Seiko TG/DTA6200 at a heating rate of $10{ }^{\circ} \mathrm{C} / \mathrm{min}$ under $\mathrm{N}_{2}$ at a flow rate of 200 $\mathrm{mL} / \mathrm{min}$. The differential scanning calorimetric (DSC) analysis was performed using a Seiko EXSTAR6200 at the heating rate of $10{ }^{\circ} \mathrm{C} / \mathrm{min}$. The Fourier-transform infrared spectra were recorded on a SHIMAZU IR Prestige-21 spectrometer to evaluate the degree of deprotection of tBA units. The adhesion tests were performed according to ASTM D3330 standard using a SHIMADZU universal testing machine AGS-X, with a 
$1 \mathrm{kN}$ (at maximum) load cell. All the adhesion tests were performed at $25{ }^{\circ} \mathrm{C}$. The peel rate for the $180^{\circ}$ peel test was $30 \mathrm{~mm} / \mathrm{min}$. Digital microscope images were acquired on a Keyence VHX-500.

\subsection{Preparation of Joints for $180^{\circ}$ Peel Tests}

A stainless steel (SUS) $430\left(150 \times 50 \times 0.5 \mathrm{~mm}^{3}\right)$ adherend was cleaned by ultrasonication in acetone for $15 \mathrm{~min}$, then in 2-propanol for $15 \mathrm{~min}$. Typically, a 15 wt\% toluene solution of the polymer was applied a poly(ethylene terephthalate) (PET) film (50 $\mu \mathrm{m}$ thickness) by a Baker type film applicator (200 $\mu \mathrm{m}$ gap). The film was dried in vacuo for $12 \mathrm{~h}$ in the dark, then cut to a 20 -mm wide. The film was pressure bonded on a SUS plate using a 2-kg hand roller by reciprocating 2 times. The $180^{\circ}$ peel test were carried out after the specimen was left to stand for over $30 \mathrm{~min}$ at room temperature.

For the dismantling treatment, the test piece was placed at a distance of $10 \mathrm{~cm}$ from the UV source (Toshiba SHL-100UVQ-2, ) at room temperature. The light intensity of 0.5-0.7 $\mathrm{mW} / \mathrm{cm}^{2}$ was measured by a UV power meter (USHIO, UIT-101) equipped with a UVD-365PD optical receiver $(330-390 \mathrm{~nm})$. Then, the test piece was placed in a preheated oven for a predetermined time, removed from the oven, then naturally cooled to room temperature. Before the treatments, the test piece was left to stand for $30 \mathrm{~min}$ at room temperature. Sole treatments, i.e., individual UV irradiation and heating, were similarly carried out.

Although the results of peel tests are influenced by the stiffness of adhesives, the $180^{\circ}$ peel test was utilized to evaluate the changes in the adhesion properties after bonding, which is important to evaluate the dismantlability.

\subsection{Determination of Gel Fraction and Swelling Ratio}


The gel fraction and swelling ratio were calculated gravimetrically by using eqs. (1) and (2), respectively.

$$
\begin{aligned}
& \text { gel fraction }(\mathrm{wt} \%)=\left(W_{\mathrm{b}}-W_{\mathrm{d}}\right) /\left(W_{\mathrm{a}}-W_{\mathrm{d}}\right) \times 100 \\
& \text { degree of swelling }(\mathrm{wt} \%)=\left(W_{\mathrm{c}}-W_{\mathrm{d}} \times a\right) /\left(W_{\mathrm{b}}-W_{\mathrm{d}}\right) \times \rho_{2} / \rho_{1} \times 100
\end{aligned}
$$

Where, $W_{\mathrm{a}}, W_{\mathrm{b}}, W_{\mathrm{c}}$, and $W_{\mathrm{d}}$ denote the weights of the dried PSA tape, the dried PSA tape with insoluble polymers after soaking in chloroform for $12 \mathrm{~h}$, the swollen PSA tape with insoluble polymers after soaking in chloroform for $24 \mathrm{~h}$, and the dried PET support film used for the PSA tape, respectively. The values of $\rho_{1}$ and $\rho_{2}$ denote the density of chloroform (= $1.49 \mathrm{~g} / \mathrm{cm}^{3}$, at r.t.) and polymer, which was assumed to be $1.2 \mathrm{~g} / \mathrm{cm}^{3}$, respectively. Considering the degree of swelling of PET support film of the PSA tape (= $123 \mathrm{wt} \%), a=1.23$ was assigned in eq. (1).

\section{Results and Discussion}

\subsection{Preparation of Reactive Acrylic Copolymers}

Reactive acrylic copolymers containing both or one of HEA and tBA units were synthesized by TERP using the ditellurides, DT-Bu or DT-Ph, with binary azo-initiators, AIBN and AMVN[15,18], and their characteristics are summarized in Table 2. The acrylic copolymers having different HEA contents from 4.0 to 39.4 mol\% with adequately high molecular weights in the order of $10^{5}$ and relatively narrow molecular weight distribution $\left(M_{\mathrm{w}} / M_{\mathrm{n}}\right)$ values were successfully synthesized using the living radical polymerization technique. In the case of HEA4 and HEA6, the values of $T_{\mathrm{g}}$ were adjusted at around $-40{ }^{\circ} \mathrm{C}$ by using $\mathrm{MA}$ as a non-reactive comonomer considering the use of the copolymers as a PSA at room temperature. Furthermore, acid catalysed deprotection of tBA units in tBA-HEA6 was conducted in solution to obtain the copolymer which has a similar HEA content and molecular weight to those for tBA- 
HEA6. Although $M_{\mathrm{n}}$ and $M_{\mathrm{w}} / M_{\mathrm{n}}$ values were slightly increased after deprotection because of intermolecular transesterification and/or esterification during the reaction, an increase in the $M_{\mathrm{n}}$ was less than $10 \%$ and the HEA content after deprotection was very close to that before deprotection, and thus AA-HEA6 is available as the model polymer for the quantitatively deprotected tBA-HEA6.

\subsection{Effects of Transesterification on Dismantlable Adhesion Properties}

The effects of acid catalysed transesterification of HEA units on dismantlable adhesion properties were investigated using the reactive acrylic copolymers containing different HEA units, i.e., HEA6, HEA18, and HEA40. As a photoacid generator, $0.4 \mathrm{wt} \%$ of NIT was added to the copolymers to prepare the PSA tapes, and the peel test specimens were photoirradiated for given time with subsequent heating at $150{ }^{\circ} \mathrm{C}$ for $5 \mathrm{~min}$. In order to exclude the influence that the interfacial interaction between the polymer and substrate is affected by heating conditions, heating temperature and time were fixed and the degree of acid catalysed transesterification was controlled by photoirradiation time, i.e., the amount of the generated acid. It was confirmed that photo decomposition of NIT in HEA6 film follows first order kinetics as reported in solution and in polystyrene films[20]. Under the present experimental conditions, the decomposition product of NIT almost linearly increased with increasing photoirradiation time, and thus it can be assumed that the amount of the generated acid is proportional to the photoirradiation time.

The results of the $180^{\circ}$ peel tests are summarized in Table 3 . In all cases the data of the untreated specimens are shown first. For HEA6, HEA18, and HEA40, the peel strength and failure mode of the untreated specimens depended on the HEA contents, that is HEA6 having less polar hydroxy groups resulted in cohesive failure due to a weak cohesive force, and HEA18 and HEA40 having more polar hydroxy groups 
resulted in the failure at the SUS interface with smaller peel strengths than that of HEA6 due to sufficient cohesive force and relatively low interfacial interaction. As shown in Figure $1(\mathrm{a})$, the $180^{\circ}$ peel strength first unexpectedly increased to reach the maximum value and then started to decrease with increasing photoirradiation time, i.e., the acid content. In the increasing region of the peel strength, all copolymers brought about cohesive failures and the adhesive layers were soluble in chloroform and THF. On the other hand, in the decreasing region of the peel strength, the failure mode turned into the failure at the PET interface and the adhesive layers contained an insoluble fraction in chloroform.

The molecular weight distributions of the soluble HEA18 obtained in the increasing region of the peel strength are shown in Figure 2. In Figure 2, the fraction corresponding to HEA18 decreased and the new shoulder peaks appeared at higher molecular weight side with increasing photoirradiation time. The molecular weight values at the peak tops of the newly appeared shoulder peaks were of the order of $10^{6}$ and significantly higher than those of HEA18, i.e., $2.2 \times 10^{5}$. These results demonstrated that intermolecular transesterification of the HEA units took place during heating and the degree of transesterification increased with increasing photoirradiation time, i.e., the acid content. The increased peel strength in this region is reasonably explained by the increased cohesive force due to the increased molecular weight, i.e., the increased chain entanglement.

The polymers obtained in the decreasing region of the peel strength were also characterized in terms of gel fraction and degree of swelling (Table 3). The gel fraction tended to increase with increasing photoirradiation time to reach nearly quantitative gel fraction. As shown in Figure 1(b), the degree of swelling decreased with increasing photoirradiation time and reached ca. $2000 \mathrm{wt} \%$ when the peel strength was reduced 
less than $10 \%$ of the initial value, i.e., 30 min photoirradiation for HEA18 and HEA 40, and 60 min photoirradiation for HEA6. These results suggested that in the peel strength decreasing region, the modulus of the adhesive layer exceeded appropriate value as a PSA[21,22] due to cross-linking and, therefore, the peel strength decreased. Compared with the untreated polymers, the $T_{\mathrm{g}}$ values were only slightly increased by cross-linking; from $-37{ }^{\circ} \mathrm{C}$ to $-31{ }^{\circ} \mathrm{C}$ for HEA18 with 30 min photoirradiation and from $-37{ }^{\circ} \mathrm{C}$ to $32{ }^{\circ} \mathrm{C}$ for HEA40 with $30 \mathrm{~min}$ photoirradiation. The results of the $T_{\mathrm{g}}$ changes are consistent with the fact that transesterification resulted in a loose network structure as recognized from the relatively large degree of swelling, i.e., $2000 \mathrm{wt} \%$. The photoirradiation time required to reach the maximum $180^{\circ}$ peel strengths shortened with increasing HEA contents because of faster progression of transesterification. In other words, it takes 15 to 30 min for the irradiation on HEA6 to start decreasing the $180^{\circ}$ peel strength while it takes only 2.5 to 10 min for the case of HEA40.

\subsection{Effects of Deprotection on Dismantling Properties}

In order to investigate the effect of deprotection of tBA units on dismantling properties, tBA-HEA6 was compared with HEA6 not containing tBA units and AA-HEA6, tBA units of which were deprotected before preparing the PSA tape. The HEA content was fixed to ca. $6 \mathrm{~mol} \%$ to exclude the effect of the transesterification of HEA units. The $180^{\circ}$ peel tests of tBA-HEA6 resulted in similar behavior to the copolymers not containing tBA units, i.e., the peel strength first increased and then decreased with increasing photoirradiation time (Table 3). However, in the case of tBA-HEA6, even in the peel strength decreasing region where tBA-HEA6 turned into insoluble in chloroform and the degree of swelling was comparable to that of HEA6, the $180^{\circ}$ peel test resulted in cohesive failures. Bubble generation was recognized in the adhesive layer of tBA-HEA6 by photoirradiation with subsequent heating due to isobutene 
evolution as we previously reported[15,17]. Obvious void formation in the adhesive layer was likewise observed for tBA-HEA10 after photoirradiation and subsequent heating, whereas no void was found for the case of HEA26 (Figure 3). In contrast, AA-HEA6 resulted in SUS and PET interfacial failures regardless to photoirradiation time and no forming was observed in the adhesive layer. It is considered that the cohesive force of tBA-HEA6 decreased by the formation of voids and thus the cohesive failure was observed even after cross-linking takes place.

The effect of the tBA units on the degree of cross-linking was studied by comparing the values of the gel fraction and the degree of swelling for HEA6, tBA-HEA6, and AA-HEA6 after photoirradiation for 10 and 15 min with subsequent heating (Table 3). HEA6 was soluble in chloroform, tBA-HEA6 resulted in nearly quantitative gel fraction with the degree of swelling in the order of $10^{3}$, and AA-HEA6 resulted in quantitative gel fraction with the degree of swelling in the order of $10^{2}$. The results obviously show that faster cross-linking took place in the order of AA-HEA6 > tBA-HEA6 > HEA6. The degree of deprotection of the tBA units to AA units in tBA-HEA6 was ca. 40 and 90\% after 10 and 25 min photoirradiation with subsequent heating, respectively. Based on these results, it is clear that the existence of AA units promote cross-linking. It is considered that AA units form cross-linking points by acid catalysed esterification. It was revealed that as a precursor of AA units, tBA units promote cross-linking, which is necessary to result in the reduction of peel strength with an interfacial failure. In fact, we previously reported that the block copolymers containing tBA segment possess superior dismantlability[15,18], and the block copolymer containing tBA segment, i.e., $\mathrm{PtBA}_{24.1}-b-\mathrm{P}\left(\mathrm{tBA}_{5.0^{-}}-c o-\mathrm{nBA}_{67.0}-c o-\mathrm{HEA}_{3.9}\right)$ (tBA-b-HEA4) resulted in significant reduction in the $180^{\circ}$ peel strength with PET interfacial failure[18], whereas the 
polymer not containing tBA units (HEA4) brought about only a slight decrease after the same dismantling treatment (Figure 4).

\section{Conclusions}

The $180^{\circ}$ peel behavior of the dismantlable adhesives consisting of the reactive acrylic copolymers with HEA and tBA units were systematically investigated by changing the amount of the acid catalyst and the copolymer compositions in order to clarify the individual role of the reactive units. The reduced degree of transesterification of HEA units resulted in an increase in the peel strength due to an increased cohesive force by an increased molecular entanglement. After the sufficient progression of transesterification, i.e., cross-linking, the peel strength decreased due to an increased modulus exceeding the appropriate region for PSAs, i.e., brittle fracture was initiated. The deprotection of tBA units promoted cross-linking because the resulting AA units participate in crosslinking by esterification. The isobutene gas evolved by the deprotection formed voids in the adhesive layer and thus the cohesive force decreased. The interfacial failure was achieved when the reduction in peel strength was accomplished by a high modulus as a result of cross-linking, whereas the cohesive failure was observed when the reduction was achieved by a decreased cohesive force. The understanding of the individual role of HEA and tBA units on dismantlable behavior revealed in the present study is essential to design superior dismantlable adhesive materials which possess not only reduced peel strength but also favorable failure modes.

\section{References}

[1] Ebe, K., Seno, H., and Horigome, K. J. Appl. Polym. Sci., 90, 436-441 (2003). 
[2] Boyne, J. M., Millan, E. J., and Webster, I. Int. J. Adhes. Adhes., 21, 49-53 (2001).

[3] Kihara, N., Ii, R., and Ogawa, A. J. Polym. Sci.:Part A: Polym. Chem., 45, 963967 (2007).

[4] Trenor, S. R., Shultz, A. R., Love, B. J., and Long, T. E. Chem. Rev., 104, 30593077 (2004).

[5] Sato, E., Tamura, H., and Matsumoto, A. ACS Appl. Mater. Interfaces. 2, 25942601 (2010).

[6] Sato, E., Hagihara, T., and Matsumoto, A. ACS Appl. Mater. Interfaces. 4, 2057-2064 (2012).

[7] Ishikawa, H., Seto, K., Shimotuma, S., Kishi, N., and Sato, C. Int. J. Adhes. Adhes., 25, 193-199 (2005).

[8] Akiyama, H., Kanazawa, S., Okuyama, Y., Yoshida, M., Kihara, H., Nagai, H., Norikane, Y., and Azumi, R. ACS Appl. Mater. Interfaces. 6, 7933-7941 (2014).

[9] Gilbert, M. D., US patent US 2007/0269659 A1. 2007 Nov. 22, 2007.

[10] Leijonmarck, S., Cornell, A., Danielsson, C.-O., Akermark, T., Brandner, B. D., and Lindbergh, G. Int. J. Adhes. Adhes., 32, 39-45 (2012).

[11] Wang, R., Xiao, X., and Xie, T. Macromol. Rapid Commun., 31, 295-299 (2010).

[12] Wang, R., and Xie, T. Langmuir. 26, 2999-3002 (2010).

[13] Kobayashi, M., Terada, M., and Takahara, A. Soft Matter. 7, 5717-5722 (2011).

[14] Inui, T., Sato, E., and Matsumoto, A. ACS Appl. Mater. Interfaces. 4, 2124-2132 (2012).

[15] Inui, T., Yamanishi, K., Sato, E., and Matsumoto, A. Macromolecules. 46, 81118120 (2013). 
[16] Yamanishi, K., Sato, E., and Matsumoto, A. J. Photopolym. Sci. Technol., 26, 239-244 (2013).

[17] Sato, E., Taniguchi, K., Inui, T., Yamanishi, K., Horibe, H., and Matsumoto, A. J. Photopolym. Sci. Technol., 27, 531-534 (2014).

[18] Inui, T., Sato, E., and Matsumoto, A. RSC Adv., 4, 24719-24728 (2014).

[19] Freitas, J. C. R., Palmeira, D. J., Oliveira, R. A., Menezes, P. H., and Silva, R. O. Magn. Reson. Chem., 50, 481-487 (2012).

[20] Okamura, H., Sakai, K., Tsumooka, M., and Shirai, M. J. Photopolym. Sci. Technol., 16, 701-706 (2003).

[21] Chang, E. P. J. Adhesion. 34, 189 (1991).

[22] Patrick, R. L., editor. Treatise on Adhesion and Adhesives: Vol. 2: Materials. New York: Marcel Dekker; 1969. 
Table 1. Synthesis of the reactive acrylic copolymers by TERP using DT-Bu and binary azoinitiators ${ }^{a}$.

\begin{tabular}{|c|c|c|c|c|}
\hline \multirow{2}{*}{ polymer } & \multirow{2}{*}{$\begin{array}{c}{[\mathrm{tBA}] /[\mathrm{MA}] /[\mathrm{nBA}] /} \\
{[\mathrm{HEA}]}\end{array}$} & \multirow{2}{*}{$\begin{array}{c}{[\mathrm{M}]^{b} /[\mathrm{AIBN}] /[\mathrm{AMVN}]} \\
/[\mathrm{DT}-\mathrm{Bu}]\end{array}$} & \multirow{2}{*}{$\begin{array}{l}\text { time } \\
\text { (h) }\end{array}$} & \multirow{2}{*}{$\frac{\text { Convn. (\%) }}{\text { tBA/MA/nBA/HEA }}$} \\
\hline & & & & \\
\hline HEA4 & 0/37/60/3 & $5650 / 1.0 / 1.4 / 1.0^{c}$ & 4.5 & $-/ 83 / 84 / 86$ \\
\hline HEA6 & 0/25/70/5 & 6032/1.0/1.2/1.0 & 6.0 & $-/ 60 / 75 / 81$ \\
\hline HEA18 & $0 / 0 / 75 / 25$ & $5600 / 1.0 / 1.2 / 1.0$ & 7.7 & -/-/65/56 \\
\hline HEA26 & $0 / 0 / 77 / 23$ & $6240 / 1.0 / 1.4 / 1.0^{c}$ & 4.0 & $-/-/ 96 / 97$ \\
\hline HEA40 & 0/0/65/35 & $5314 / 1.0 / 1.2 / 1.0$ & 6.8 & $-/-/ 70 / 77$ \\
\hline tBA-HEA6 & $30 / 0 / 65 / 5$ & $5532 / 1.0 / 1.2 / 1.0$ & 5.5 & $81 /-/ 75 / 62$ \\
\hline tBA-HEA10 & $43 / 0 / 45^{d} / 11$ & 6149/1.0/1.2/1.0 & 5.0 & $84 /-/ 88^{d} / 97$ \\
\hline
\end{tabular}

${ }^{a}$ Polymerization conditions: comonomer/anisole $=1 / 1$ in weight at $60{ }^{\circ} \mathrm{C}$. ${ }^{b}$ Total concentration of comonomers. ${ }^{c} \mathrm{DT}-\mathrm{Ph}$ was used instead of DT-Bu. ${ }^{d}$ 2EHA was used instead of nBA. 
Table 2. Characteristics of the reactive acrylic copolymers.

\begin{tabular}{|c|c|c|c|c|}
\hline Polymer & Sequence structure & $M_{\mathrm{n}} / 10^{5}$ & $M_{\mathrm{w}} / M_{\mathrm{n}}$ & $T_{\mathrm{g}}\left({ }^{\circ} \mathrm{C}\right)$ \\
\hline HEA4 & $\mathrm{P}\left(\mathrm{MA}_{26.4}-c o-\mathrm{nBA}_{69.6}-c o-\mathrm{HEA}_{4.0}\right)$ & 1.78 & 1.57 & -37 \\
\hline HEA6 & $\mathrm{P}\left(\mathrm{MA}_{20.7}-c o-\mathrm{nBA}_{73.3}-c o-\mathrm{HEA}_{6.0}\right)$ & 2.71 & 1.56 & -38 \\
\hline HEA18 & $\mathrm{P}\left(\mathrm{nBA}_{82.5}-c o-\mathrm{HEA}_{17.5}\right)$ & 1.98 & 1.92 & -37 \\
\hline HEA26 & $\mathrm{P}\left(\mathrm{nBA}_{74.2}-c o-\mathrm{HEA}_{25.8}\right)$ & 3.18 & 1.94 & -39 \\
\hline HEA40 & $\mathrm{P}\left(\mathrm{nBA}_{60.6}-c o-\mathrm{HEA}_{39.4}\right)$ & 2.04 & 2.47 & -37 \\
\hline tBA-HEA6 & $\mathrm{P}\left(\mathrm{tBA}_{30.5}-c o-\mathrm{nBA}_{64.0^{-}}-c o-\mathrm{HEA}_{5.5}\right)$ & 2.57 & 1.48 & -27 \\
\hline tBA-HEA10 & $\mathrm{P}\left(\mathrm{tBA}_{26.5}-c o-2 \mathrm{EHA}_{63.5^{-}}-c o-\mathrm{HEA}_{10.0}\right)$ & 2.30 & 2.40 & -39 \\
\hline AA-HEA $6^{a}$ & $\mathrm{P}\left(\mathrm{AA}_{22.3}-c o-\mathrm{nBA}_{71.7}-c o-\mathrm{HEA}_{6.0}\right)$ & 2.81 & 1.85 & -12 \\
\hline
\end{tabular}

${ }^{a}$ Obtained by deprotection of tBA-HEA6. 
Table 3. Dismantlable properties of the reactive acrylic copolymers having sequence structures ${ }^{a}$.

\begin{tabular}{|c|c|c|c|c|c|c|}
\hline polymer & $\begin{array}{l}\text { irrad. } \\
\text { time } \\
\text { (min) }\end{array}$ & $\begin{array}{c}\text { peel } \\
\text { strength } \\
\text { (N/20 mm) }\end{array}$ & $\begin{array}{l}\text { relative } \\
\text { value }^{b}\end{array}$ & failure mode ${ }^{c}$ & $\begin{array}{c}\text { gel } \\
\text { fraction } \\
\text { (wt } \%)\end{array}$ & $\begin{array}{c}\text { degree of } \\
\text { swelling } \\
\text { (wt\%) }\end{array}$ \\
\hline \multirow[t]{7}{*}{ HEA6 } & untreated & 8.18 & 1 & cohesive & soluble & - \\
\hline & 10 & 11.32 & 1.38 & cohesive & soluble & - \\
\hline & 15 & 17.73 & 2.17 & cohesive & soluble & - \\
\hline & 30 & 3.60 & 0.44 & PET & 87 & 3000 \\
\hline & 40 & 2.21 & 0.27 & PET & 97 & 2300 \\
\hline & 50 & 1.22 & 0.15 & PET & 89 & 2300 \\
\hline & 60 & 0.55 & 0.067 & PET & $\sim 100$ & 1600 \\
\hline \multirow[t]{5}{*}{ HEA18 } & untreated & 4.26 & 1 & SUS & soluble & - \\
\hline & 2.5 & 20.54 & 4.82 & cohesive & soluble & - \\
\hline & 10 & 33.23 & 7.80 & cohesive & soluble & - \\
\hline & 15 & 3.91 & 0.92 & PET & 88 & 4000 \\
\hline & 30 & 0.17 & 0.04 & PET & 81 & 1800 \\
\hline \multirow[t]{5}{*}{ HEA40 } & untreated & 3.84 & 1 & SUS & soluble & - \\
\hline & 2.5 & 11.35 & 2.96 & SUS + cohesive & soluble & - \\
\hline & 10 & 6.18 & 1.61 & PET & 53 & 2700 \\
\hline & 15 & 3.37 & 0.88 & PET & 91 & 2500 \\
\hline & 30 & 0.41 & 0.01 & PET & 79 & 2000 \\
\hline \multirow[t]{5}{*}{ tBA-HEA6 } & untreated & 3.75 & 1 & SUS & soluble & - \\
\hline & 10 & 12.37 & 3.30 & cohesive & 87 & 3600 \\
\hline & 15 & 3.91 & 1.04 & cohesive & $\sim 100$ & 1900 \\
\hline & 30 & 2.82 & 0.75 & cohesive & n.d. ${ }^{d}$ & n.d. ${ }^{d}$ \\
\hline & 50 & 1.66 & 0.44 & cohesive + PET & n.d. ${ }^{d}$ & n.d. ${ }^{d}$ \\
\hline \multirow[t]{4}{*}{ AA-HEA6 } & untreated & stick slip $^{e}$ & - & SUS & soluble & - \\
\hline & 10 & stick slip $^{e}$ & - & SUS+PET & $\sim 100$ & 560 \\
\hline & 15 & stick slip $^{e}$ & - & SUS+PET & $\sim 100$ & 260 \\
\hline & 30 & stick slip $^{e}$ & - & SUS+PET & n.d. ${ }^{d}$ & n.d. ${ }^{d}$ \\
\hline
\end{tabular}

${ }^{a}$ Containing $0.4 \mathrm{wt} \%$ NIT. The $180^{\circ}$ peel test was performed after photoirradiation at r.t. and subsequent heating at $150{ }^{\circ} \mathrm{C}$ for $5 \mathrm{~min}$. ${ }^{b}$ The values of peel strength after treatment relative to that before treatment. ${ }^{c}$ Cohesive: cohesive failure, PET: PET interfacial failure, SUS: SUS interfacial failure. ${ }^{d}$ Not determined. ${ }^{e}$ Stick slip failure was observed due to too high $T_{\mathrm{g}}$ of AA-HEA6 as a PSA. 


\section{Captions to Figures}

Figure 1. Plots of (a) the $180^{\circ}$ peel strength and (b) degree of swelling vs. photoirradiation time for HEA6 (circle), HEA18 (triangle), and HEA40 (square): Peel test specimens were subsequently heated at $150{ }^{\circ} \mathrm{C}$ for 5 min after photoirradiation: Polymers were soluble (open symbol) and insoluble in chloroform (closed symbol).

Figure 2. GPC chromatograms for untreated HEA18 (-), HEA18 after photoirradiation for $2.5(---)$ and $10 \mathrm{~min}(-\cdot-)$ with subsequent heating at $150 \mathrm{C}$ for $5 \mathrm{~min}$. The inserted numbers denote the molecular weight at the peak top.

Figure 3. Digital microscope images of the adhesive layer after photoirradiation for $1 \mathrm{~h}$ with subsequent heating at $100{ }^{\circ} \mathrm{C}$ for $1 \mathrm{~h}$. (a) HEA26 containing $0.6 \mathrm{wt} \%$ of NIT and (b) tBA-HEA10 containing $0.5 \mathrm{wt} \%$ of NIT ( $0.8 \mathrm{~mol} \%$ relative to the tBA unit).

Figure 4. Values of $180^{\circ}$ peel strength for $\mathrm{PtBA}_{24.1}-b-\mathrm{P}\left(\mathrm{tBA}_{5.0}-c o-\mathrm{nBA}_{67.0}-c o-\mathrm{HEA}_{3.9}\right)$ (tBA-b-HEA4, $M_{\mathrm{n}}=2.39 \times 10^{5}, M_{\mathrm{w}} / M_{\mathrm{n}}=1.48$ )[18] and HEA4 before (gray solid bar) and after photoirradiation for $1 \mathrm{~h}$ and subsequent heating at $100{ }^{\circ} \mathrm{C}$ for $1 \mathrm{~h}$ (red open bar). 


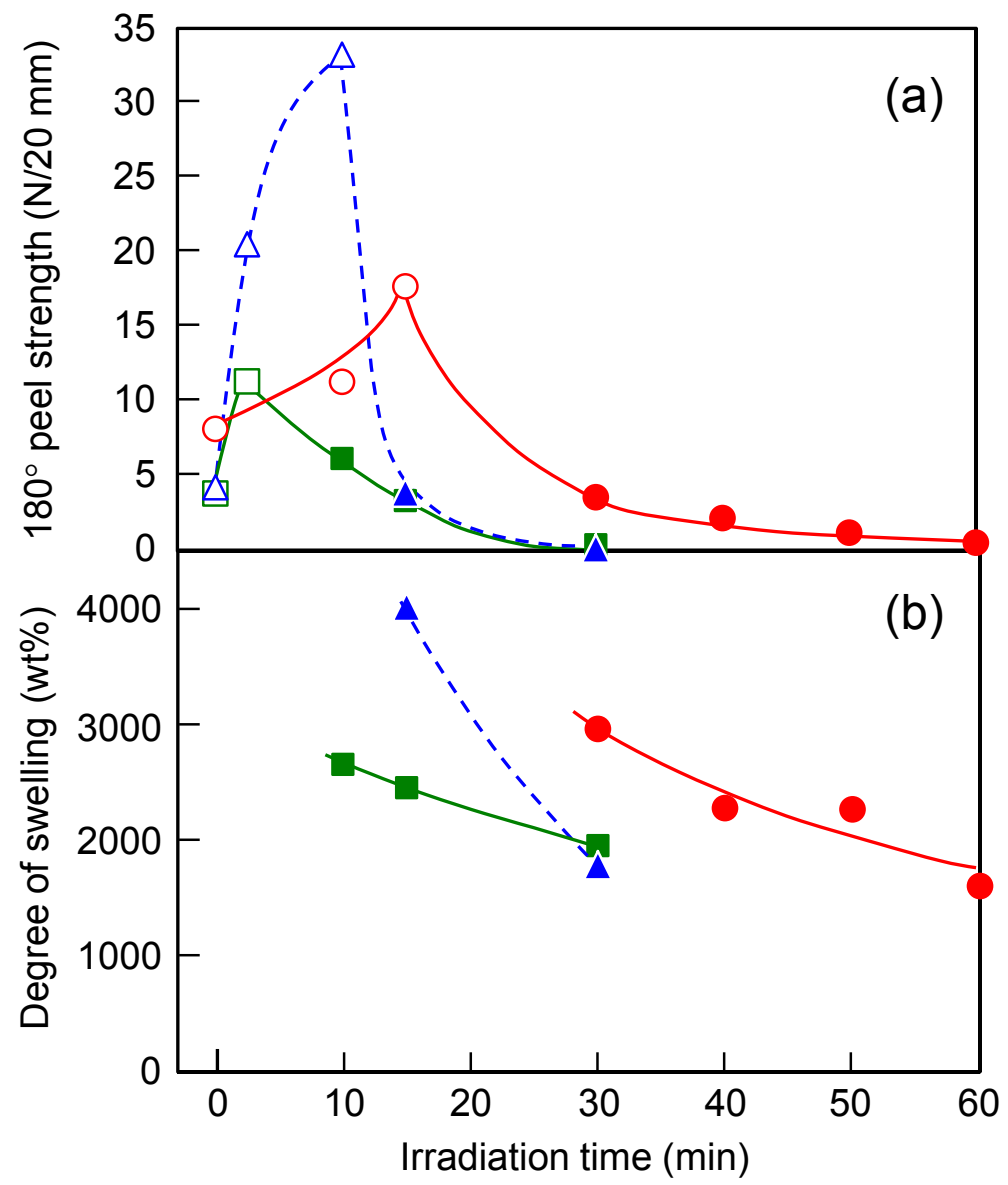

Figure 1. Plots of (a) the $180^{\circ}$ peel strength and (b) degree of swelling vs. photoirradiation time for HEA6 (circle), HEA18 (triangle), and HEA40 (square): Peel test specimens were subsequently heated at $150{ }^{\circ} \mathrm{C}$ for 5 min after photoirradiation: Polymers were soluble (open symbol) and insoluble in chloroform (closed symbol). 


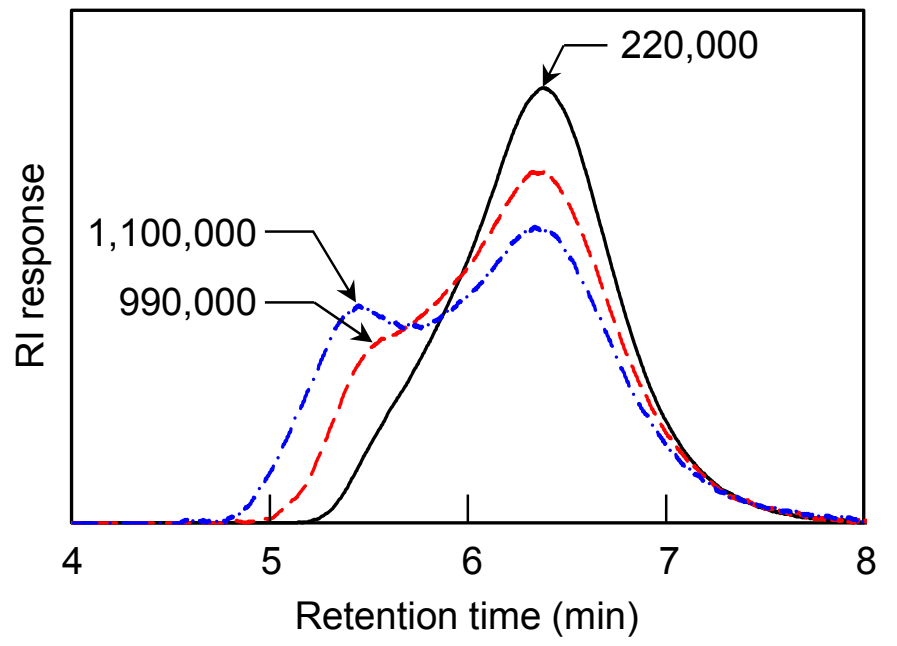

Figure 2. GPC chromatograms for untreated HEA18 (-), HEA18 after photoirradiation for $2.5(---)$ and $10 \mathrm{~min}(-\cdot-)$ with subsequent heating at $150 \mathrm{C}$ for $5 \mathrm{~min}$. The inserted numbers denote the molecular weight at the peak top. 

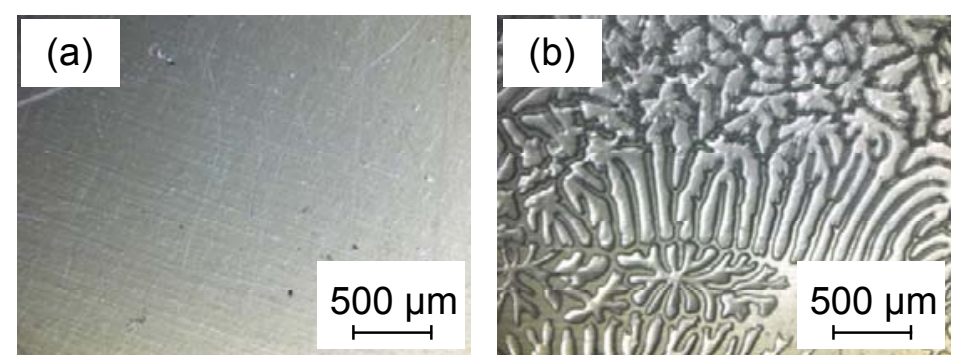

Figure 3. Digital microscope images of the adhesive layer after photoirradiation for $1 \mathrm{~h}$ with subsequent heating at $100{ }^{\circ} \mathrm{C}$ for $1 \mathrm{~h}$. (a) HEA26 containing $0.6 \mathrm{wt} \%$ of NIT and (b) tBA-HEA10 containing $0.5 \mathrm{wt} \%$ of NIT ( $0.8 \mathrm{~mol} \%$ relative to the tBA unit). 


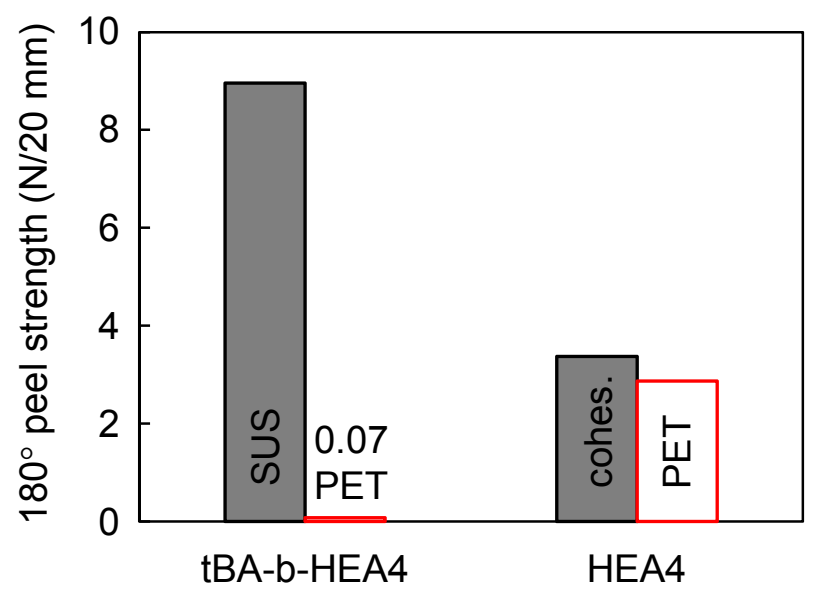

Figure 4. Values of $180^{\circ}$ peel strength for $\mathrm{PtBA}_{24.1}-b-\mathrm{P}\left(\mathrm{tBA}_{5.0}-c o-\mathrm{nBA}_{67.0}-c o-\mathrm{HEA}_{3.9}\right)$ (tBA-b-HEA4, $M_{\mathrm{n}}=2.39 \times 10^{5}, M_{\mathrm{w}} / M_{\mathrm{n}}=1.48$ )[18] and HEA4 before (gray solid bar) and after photoirradiation for $1 \mathrm{~h}$ and subsequent heating at $100{ }^{\circ} \mathrm{C}$ for $1 \mathrm{~h}$ (red open bar). 